\title{
TEMPO DE IMPERMANÊNCIA: TEATRO EM PENITENCIÁRIAS FEMININAS
}

\author{
Tatiana Cardoso da Silva ${ }^{1}$ \\ Eduardo Cristiano Hass da Silva ${ }^{2}$
}

\begin{abstract}
Resumo:
Este artigo apresenta o projeto: "Tempo de Impermanência: Teatro em Penitenciárias Femininas do Rio Grande do Sul”, ação de extensão proposta por professora e alunos do curso de Graduação em Teatro: Licenciatura, da Universidade Estadual do Rio Grande do Sul. O projeto tem como foco ações teatrais direcionadas a dois presídios da $1^{\text {a }}$ Delegacia Penitenciária Regional do Estado do Rio Grande do Sul, sendo a Penitenciária Modulada de Montenegro (PMM) e o Presídio Estadual Feminino de Torres (PEFT). Ao longo do texto são discutidas a invisibilidade do encarceramento feminino e as possibilidades de realização de ações teatrais dentro das penitenciárias, bem como são apontados alguns dos caminhos a serem percorridos pelo projeto, e parte dos resultados já obtidos. $\mathrm{O}$ projeto aqui apresentado sustenta-se na possibilidade de atuação teatral em espaços não convencionais e na indissociabilidade entre: ensino, pesquisa e extensão, no meio acadêmico, dialogando com autores como Brook (1995), Maria da Gloria Gohn (2004) e Henri Bergson (2006).
\end{abstract}

Palavras-chave: Extensão acadêmica. Penitenciárias Femininas. Teatro.

\section{Introdução}

O presente trabalho tem por objetivo principal apresentar o projeto: "Tempo de Impermanência: Teatro em Penitenciárias Femininas do Rio Grande do Sul”, ação de extensão a partir do Edital PROEXT/2015, proposta por professora e alunos do curso Graduação em Teatro: Licenciatura, da Universidade Estadual do Rio Grande do Sul. Tal projeto, em andamento, tem como foco ações teatrais direcionadas a dois presídios da $1^{\mathrm{a}}$ Delegacia Penitenciária Regional do Estado do Rio Grande do Sul, sendo a Penitenciária Modulada de Montenegro (PMM) e o Presídio Estadual Feminino de Torres (PEFT).

A proposta aqui apresentada articula elementos bases sobre: Cultura, Educação, Direitos Humanos e Justiça. Desta forma, o texto encontra-se organizado em quatro tópicos. No primeiro, intitulado: "Invisibilidade do encarceramento feminino: pontos para reflexão", discutimos alguns elementos a respeito da invisibilidade do encarceramento feminino, salientando a ausência de instituições prisionais que atentem para as particularidades das mulheres. Em seguida, sob o título: “Tempo de Impermanência: Teatro

\footnotetext{
${ }^{1}$ Professora do curso Graduação em Teatro: Licenciatura, da Universidade Estadual do Rio Grande do Sul (UERGS). Doutoranda pelo Programa de Pós-graduação em Artes Cênicas da Universidade Federal do Rio Grande do Sul (UFRGS). Atriz e diretora. (tatianacardoso8@gmail.com).

${ }^{2}$ Doutorando em Educação pela Universidade do Vale do Rio dos Sinos (Unisinos), graduando em teatro pela Universidade Estadual do Rio Grande do Sul (UERGS). (eduardohass.he@ gmail.com).
} 
em Penitenciárias Femininas do Rio Grande do Sul" apresentamos o projeto em andamento, que visa, como anteriormente citado, a realização de ações teatrais direcionadas a dois presídios da $1^{\text {a }}$ Delegacia Penitenciária Regional do Estado do Rio Grande do Sul (PMM e PEFT). No terceiro tópico, "O que buscamos e o que faremos", explicitamos como estamos concretizando esta proposta. Para finalizar, em: "Frutos a colher," apresentamos alguns dos resultados parciais obtidos, bem como algumas das ações a serem percorridas.

\section{1- Invisibilidade do encarceramento feminino: pontos para reflexão.}

"O sistema penal foi feito e pensado por homens, para homens" (PFALLER, 2017). A frase da Irmã Petra Pfaller ${ }^{3}$, coordenadora da questão da mulher na Pastoral Carcerária, proferida em entrevista ao Jornal Sul 21 no ano de 2017, evidencia um dos primeiros problemas a serem elencados sobre o encarceramento feminino. No entanto, este é apenas um dos enfoques.

Petra Pfaller (2017) revela elementos importantes para pensarmos as condições das mulheres que se encontram privadas de liberdade nos presídios brasileiros. Tomando dados produzidos e apresentados pelo Informativo do Departamento Penitenciário Nacional (Infopen); Pfaller (2017) destaca que o Brasil tem, atualmente, a quinta maior população carcerária feminina no mundo, chegando a aproximadamente 37 mil mulheres presas, número que nos últimos 15 anos aumentou em 567\%, ao passo que a média do crescimento dos cárceres para homens foi de 220\%. Na reportagem, a missionária destaca que a realidades das mulheres presidiárias tende a ser menos vista que a dos homens, embora seja tão problemática quanto: celas superlotadas, presídios mistos, com a existência de assédio; poucas horas de sol; doenças de pele causadas pela sujeira dos ambientes; depressão e abandono, entre outros fatores.

A Invisibilidade das mulheres encarceradas não se dá apenas pelo Estado, mas também no cotidiano e nas mídias. É comum encontrarmos reportagens abordando apenas o cárcere masculino, como a exibida pelo Profissão Repórter ${ }^{4}$, em 10 de novembro de 2015, apenas para citar um exemplo, na qual o programa atenta para a superlotação do Presídio Central de Porto Alegre/RS, que conta com 2400 detentos acima da sua capacidade. Outro

\footnotetext{
${ }^{3}$ Petra Pfaller nasceu em Munique, na Alemanha. Entrou na congregação Irmãs Missionárias de Cristo e, aos 26 anos, ainda com votos temporários, veio para o Brasil, no início dos anos 1990. Graduada em direito, recebeu o convite para trabalhar junto à Pastoral Carcerária, na evangelização e fiscalização dos presídios em todo o Brasil. Atualmente, é coordenadora da questão das mulheres presas dentro da organização.

${ }^{4}$ Reportagem disponível em: https://www.youtube.com/watch?v=K1Rjfx3OiqM. Acesso em 17/06/2018.
} 
tema particularmente sensível que se apresenta em alguns programas é o preconceito a sujeitos homossexuais em presídios, como pode se observar na reportagem: "Presos falam com Cazé sobre relação com homossexuais no presídio', Liga" e exibida em 19 de julho de 2017.

Ao afirmar que "O sistema penal foi feito e pensado por homens, para homens", Pfaller (2017) pode referir-se a algumas particularidades de ser mulher, as quais o presídio não consegue atender, tais como a distância e o relacionamento com os filhos, presença de mulheres grávidas e ausência de visitas. As mulheres encarceradas são comumente visitadas apenas pelas mães, que costumam ser pobres e residir longe. No caso de homens encarcerados, estes ainda recebem a visita de suas esposas, o que em geral, não acontece com as mulheres no cárcere. Destaca-se o caso das mães separadas de filhos recém nascidos, que têm de ficar aos cuidados de familiares, ou irem para a adoção, e até mesmo casos de partos feitos na cadeia, com as mães algemadas. Além disso, existem as especificidades do corpo feminino, sendo comum encontrar mulheres com caroços na mama e no útero, sem assistência médica adequada, bem como a falta de absorventes higiênicos, cabendo às detentas o improviso com panos ou miolos de pão. Ou seja, mesmo considerando a importância do tema em geral, é necessário que se discuta e torne visível também, os graves problemas que as mulheres encarceradas enfrentam.

\section{2- Tempo de Impermanência: Teatro em Penitenciárias Femininas do Rio Grande Do Sul.}

É um projeto em construção, uma forma de resistência ao apagamento e ao esquecimento da mulher encarcerada, tomando o teatro como principal ferramenta e forma de expressão. É um movimento que pretende acender algumas luzes, mesmo que bruxuleantes, sobre o problema da invisibilidade do encarceramento feminino. Antes de adentrarmos na apresentação do projeto em desenvolvimento, cabem algumas colocações em relação ao teatro e ao trabalho com sujeitos privados de liberdade.

Segundo André Brito Correia (2003) embora se tenha a tendência em pensar o teatro como aquele ocorrido dentro do modelo de palco italiano, fruto da ascensão da burguesia, o teatro tem acontecido atualmente, nos mais variados espaços nãoconvencionais: praças, igrejas, museus, ruas, etc., ou seja, espaços que não foram pensados

\footnotetext{
${ }^{5}$ Reportagem disponível em: https://www.youtube.com/watch?v=cOPSc4amfQI. Acesso em 17/06/2018.
} 
ou construídos para tal. Para o autor pode-se falar da existência de um teatro feito fora dos teatros, que “(...) não é equivalente ao teatro que se faria nos teatros retirando-lhes simplesmente as paredes" (CORREIA, 2003, p. 4). Dessa forma, "a utilização de um espaço não convencional para a atuação teatral permite ampliar a nossa perspectiva e converter objetos, dispositivos, equipamentos, ambientes e referências geográficas em elementos de ficção, imaginação e surpresa" (CORREIA, 2003, p. 8). Dentre os espaços investigados pelo autor se encontram os estabelecimentos prisionais ${ }^{6}$, os jardins e os bairros.

Assim como a experiência de Correia (2003), outras atividades tem sido desenvolvidas com sujeitos em situação de privação de liberdade. Trocando correspondências com jovens privados de liberdade, Nilda Stecanella e Carmen Craidy (2010) analisam os textos produzidos por estes sujeitos. Tomando as juventudes como uma categoria social construída, as autoras tentam identificar as formas de ser jovem em contextos de privação de liberdade bem como a liberdade possível de ser construída nos espaços de confinamento.

Cada um com suas especificidades (um com o teatro e outro com correspondências), os projetos citados voltam-se para sujeitos privados de liberdade. No entanto, mesmo considerando-os fundamentais e importantes, queremos dizer que mencioná-los aqui, nos servem como uma pequena amostra deste tipo de ações que visam trabalhar com homens, sejam presidiários ou jovens tidos como infratores. Não circulam muitas informações ou notícias de projetos como estes, sendo desenvolvidos especificamente com mulheres apenadas. Desta forma, uma das particularidades do projeto aqui apresentado é justamente atentar para mulheres presas.

O projeto: “Tempo de Impermanência: Teatro em Penitenciárias Femininas do Rio Grande Do Sul”, consiste em uma ação teatral em dois presídios da 1a. Delegacia Penitenciária Regional do Estado do Rio Grande do Sul: Penitenciária Modulada de Montenegro e o Presídio Estadual Feminino de Torres. A ação pretende levar o teatro às penitenciárias do RS, com ações que vão desde a apresentação do espetáculo "O Jardim das Cerejeiras", a partir do texto de Anton Tchekov, debates com o público, oficinas de teatro e a criação de cenas teatrais feitas pelas próprias apenadas, que devem ser levadas a público.

\footnotetext{
${ }^{6}$ Em relação ao teatro em um presídio, a experiência analisada pelo autor foi realizada no Estabelecimento Prisional de Coimbra, de 17 a 20 de dezembro de 2003. A metodologia empregada pautou-se no Teatro do Oprimido, de Augusto Boal, sendo o espetáculo pensado especificamente para o espaço prisional. Segundo Correia (2003), os atores eram todos presidiários e, a peça apresentava o cotidiano na prisão sem ser um teatro-documento, com a autoria dos próprios reclusos.
} 
O projeto é uma proposta de professora e alunos do curso Graduação em Teatro: Licenciatura, da Universidade Estadual do Rio Grande do Sul. O projeto de extensão, criado em contexto acadêmico, tem por objetivo trocar experiências de transformações internas, de mudança de ponto de vista, de saltos de interpretação e sensibilização para dentro de si, tanto aos agentes da ação quanto ao público ao qual se dirige, em constante troca.

Diversas relações se estabelecem e a raiz do jogo teatral, elevando aqui a interação entre corpos, a testemunha e cumplicidade que advêm de constituirmos a mesma espécie, essa troca que o teatro permite, pode se configurar em todo e qualquer lugar. Assim como “aqui fora”, também há uma vida acontecendo dentro de uma prisão. É disso que falamos, da tentativa de experimentarmos a impermanência libertadora de tempo e espaço que o teatro pode proporcionar, numa possibilidade de presentificar outras formas de nossa condição humana, tão misteriosa, quanto passível de mudança, para além de muros, sejam eles de concreto ou de sensações.

A montagem teatral "O Jardim das Cerejeiras" foi criada no semestre 2012.B, dentro da Uergs, no componente curricular: Oficina Montagem. Por ter sido uma experiência instigadora como conteúdo disciplinar para o grupo envolvido, alunos e professora investiram na continuidade e aprofundamento daquele processo através de um ano de pesquisas em 2013 no projeto: “Ação psicofísica: o ator no universo tchekoviano", contemplado pelo Edital Inicie/Uergs 2013. A pesquisa teve como foco o estudo e o desenvolvimento das ações psicofísicas no trabalho do ator, buscando elementos técnicos e poéticos para corporificar a poesia do texto de Tchekhov. Em 2014, a mesma equipe de alunos e professores foi contemplada dentro do Edital Proex/Uergs 2014, com o projeto de extensão "O Jardim das Cerejeiras, Circuito Universitário 2014", no qual efetivou a circulação do espetáculo por quatro universidades do interior do estado do Rio Grande do Sul. Estas experiências fortaleceram o grupo, que mesmo sem os recursos financeiros normalmente exigidos para tal, como por exemplo, para o deslocamento e produção artística de um grande grupo entre cidades, ao realizarem a circulação, só consolidaram a importância e o desejo da continuidade daquele projeto.

Na época da criação do espetáculo, ainda dentro da disciplina do currículo do curso, o texto "O Jardim das Cerejeiras" foi eleito por sua beleza, profundidade poética e por ter feito ecoar no grupo a necessidade de acordar aspectos de temas tão pertinente aos dias de hoje, tais como: a dinâmica da impermanência, as transformações iminentes, o indizível das 
situações cotidianas e a necessidade de adaptação às transições da vida. A peça conta a história de Liuba Andreiêvna, que depois de cinco anos distante, volta para a casa onde cresceu e viveu toda sua vida, uma grande propriedade, onde há um imenso jardim das cerejeiras. Esse lugar, que guarda a memória de seu passado e de sua família, está prestes a ser perdido, devido à sua falência. Diante dessa possibilidade, Lopakhine, filho de um antigo criado da família, que ascendeu como negociante, coloca a necessidade do loteamento do pé de cereja para sanar as dívidas da família. Entretanto, Liuba e seu irmão Gaiév, não querem se desfazer da casa de infância, mas ainda assim, a propriedade vai a leilão. O Jardim das Cerejeiras trata da decadência de um modo específico de vida e da constante necessidade de mudança.

Nossa montagem de "O Jardim das Cerejeiras" é tratada numa perspectiva contemporânea, atritando o conceito de representação apenas como uma imitação da realidade, de forma naturalista. Busca-se uma atuação que se relaciona com o texto ou com a fábula de forma aberta, numa tentativa mais de comentá-lo e traduzi-lo, do que ilustrá-lo. Pretendeu-se presentificar alguns aspectos do texto, relacionando-os à vida pessoal do ator e suas memórias, o que determinou pontes importantes para a criação da teatralidade da cena.

Nos interessa, com essa montagem, o reconhecimento daquilo que os personagens de Tchekov evocam e fazem ecoar em nós: as paixões humanas, as emoções, as frustrações, a nostalgia como uma forma de renúncia ao presente, nossas pequenas impotências privadas dentro de uma sociedade em constante mudança, nossa condição de seres humanos eternamente postos à prova diante dos acontecimentos do mundo, mas ainda assim, a sintonia com um intermitente gosto pela vida. Brook (1995) confirma o sentido que tentamos dar ao nosso trabalho, quando comenta sobre os personagens de Tchekhov:

\footnotetext{
É essencial compreender que não se trata de peças que giram em torno de pessoas letárgicas. São pessoas hipervivazes situadas num mundo letárgico, forçadas a dramatizar os mínimos acontecimentos em função de um apaixonado desejo de viver. Não desistiram. (BROOK, 1995, p. 214.)
}

Conforme destacamos ainda na introdução, este trabalho centra-se na articulação entre: Cultura, Educação e Direitos Humanos e Justiça. Esses elementos são tensionados a partir da conexão entre teatro, criação artística, memória e mulheres em situação carcerária. Dessa forma, a prática aqui proposta dialoga com autores do campo das ciências sociais que trabalham com a situação de cárcere ou violência às mulheres, bem como autores da área 
artísticas, como Constantin Stanislavski, Jerzy Grotowski e Eugenio Barba e também da filosofia, como Michel Foucault e Henri Bergson.

Para continuarmos tecendo conexões entre nosso jardim das cerejeiras e o das mulheres a quem este projeto se refere, é preciso que nos voltemos ao momento em que estes dois mundos se configuraram como um único jardim, no qual aromas e cores diferentes foram partilhados. Nós voltamos à apresentação deste espetáculo realizada no dia 15 de outubro de 2013, na Penitenciária Modulada de Montenegro, nosso primeiro contato com o público penitenciário, numa breve parceria entre instituições, mesmo antes da elaboração deste projeto que é tratado aqui. Nos momentos finais da peça, os atores, personagens lentamente, um a um, olham pela última vez e se despedem das paredes da antiga casa da família que devem abandonar. Liuba, a personagem de Tchekov, diz: "Vou ficar mais um minuto só, aqui. É como se eu nunca tivesse visto essas paredes; como eram os tetos desta casa. E de repente vejo; e sinto um desejo por isso tudo, carinho... amor..." (TCHEKOV, 2011, p. 77) Sabemos que paredes são feitas de tijolos e cimento, que podem parecer sólidas, sem vida, estáticas e que limitam espaços. Mas ainda assim, na fala da personagem Liuba, Tchekov nos convoca a dar um outro significado às paredes da casa, como o contorno do vivido, o abrigo das experiências humanas, o calor e as memórias de quem a habitou.

No caso de nosso Jardim das Cerejeiras, as paredes da casa de Liuba, que evocavam uma história, uma memória, um afeto, dos quais os personagens se despediam, metaforicamente, naquela apresentação da penitenciária, criaram rostos, olhos e lágrimas. Assim como os personagens, as pessoas à nossa frente, mostravam que também tinham seus próprios sentidos sobre paredes, memórias e despedidas. Nesse território, a insuficiência diante da realidade, das personagens tchekovianas ecoava e se conectava àquele público. Fomos nos sentindo olhados de uma forma diversa e ao mesmo tempo sincrônica, plena de conexões que se estendiam entre nós, artistas e apenadas. Percebemos sensorialmente que naquele momento, a peça preenchia-se de um sentido outrora não vivenciado por nós, e que tal sentido, fora criado e recriado na relação com aquelas pessoas e lugares determinados, no momento do evento teatral.

Chegamos então a este ponto, o ponto que nos move, no qual desejamos voltar àquele lugar - entendendo àquele lugar, não simplesmente como um ponto no espaço, mas como um território que nos chama, um espaço de subjetividade e de potências criativas possíveis. Buscamos aqui recriar um novo sentido, para nós e, esperamos, para elas. Estimular um 
processo pelo qual outras formas de ver possam ser geradas, anunciando, através do presídio, do teatro e da ficção de Tchekov, uma outra possibilidade de protagonismo, desta vez, de vidas reais. Vislumbramos com aquela primeira experiência de fazer teatro em um presídio, o efeito fertilizador que este trabalho pode promover, e de como o teatro pode ecoar neste público de tantas maneiras, mas sobretudo, desejamos que seja através do processo que entendemos como empoderamento. Partimos do pressuposto colocado por Maria da Gloria Gohn, ao comentar como o termo empoderamento pode ser tratado:

\footnotetext{
(...) referindo-se ao processo de mobilizações e práticas destinadas a promover e impulsionar grupos e comunidades - no sentido de seu crescimento, autonomia, melhora gradual e progressiva de suas vidas (material e como seres humanos dotados de uma visão crítica da realidade social) (...).(GOHN, 2004, p. 23).
}

Nesse sentido, nos interessa trazermos esse conceito para o debate, atrelado ao fazer teatral, junto a esse público, exercitando-o também nós, junto com as apenadas. Elas, como possíveis agentes transformadores de sua história e de seu contexto, bem como a nós mesmos, em nossas perspectivas artísticas, nas quais o empoderamento também pode se ligar a autonomia do próprio processo formativo e criativo, na importância da sensibilização individual para a configuração da experiência coletiva ou até mesmo, na própria escolha dos espaços onde o teatro pode acontecer. O fruto artístico aparece como resultado dos borramentos de diferentes vivências e expressões humanas. Vislumbramos que esta percepção pode se estender para além de um resultado ou fruição artístico em nós ou em cada apenada, contribuindo para uma tomada de consciência no protagonismo de nossas próprias vidas, mas também se inserindo em outras instâncias de nossas ações ou percepções.

Essa percepção e expressão de opinião própria, assim, poderia se estender as demais interações sociais que nós e aquelas mulheres partilhamos. Mas, para tanto, é preciso dar um passo de cada vez, reencontrar o propulsor que nos levou aquele lugar, nosso terreno comum, nosso jardim, nosso Teatro, conforme Brook:

\footnotetext{
O teatro não tem categorias, é sobre a vida. Este é o único ponto de partida e dele nada é fundamental. Teatro é vida (...) mas uma vida em forma mais concentrada, mais condensada no tempo e no espaço. (BROOK, 1999, p.7-9).
}

Bergson (2006) também nos move e nos abre o caminho nas impermanências potentes, quando diz que: as memórias se recriam e atualizam o tempo todo, que imaginação e lembrança se confundem, provocando conexões com o tempo presente, ou quando diz que 
podemos buscar na imaginação, as equivalências que melhor se encaixem na atualização dos acontecimentos lembrados. Favorecendo um meio pelo qual os acontecimentos se expressem, faz-se de certa maneira, que eles possam acontecer de novo, mas de uma outra forma, diferente.

No nosso caso, pensar em memória, ao reviver o texto de Tchekov, é pensar em recriação de si e do meio. É pensar em paredes e limites humanos que não são estáticos. Paredes que são olhos, que possuem vida, atribuem sentido, experimentam, refletem e podem mover-se; mesmo que está livre expressão, essa liberdade de pensamento, opinião e ação, se constitua e se erga em um cárcere, onde necessariamente, as paredes privam. No momento do nosso teatro, as paredes da casa familiar prestes a ser abandonada, as reações da plateia naquela apresentação na penitenciária em Montenegro, as paredes gradeadas do presídio, os corpos dos atores, suas emoções e memórias, bem como das apenadas, eram cores que se confundiam, se misturavam e compunham um outro quadro, uma outra visão. Naquela experiência, os limites concretos dos muros foram implodidos e o espaço diluiu-se, num evento de relação e de movimento.

O teatro e a cultura, assim como a vida de muitas daquelas mulheres, muitas vezes é colocado na margem da organização política e social, na qual as grandes narrativas e valores do mercado parecem ser mais importantes que os mais caros valores humanos. Mas o teatro, que é humano e a ele se dirige, encontra o que dizer ou a quem dizer, a partir da potência do vivo, do que não para de nascer e não cessa de morrer, na impermanência. Uma experiência teatral viva, no espaço de uma penitenciária, propõe o desencadeamento potente de novos olhares sobre o presente destas mulheres, quando a subjetividade pessoal e coletiva, provocada pela imaginação e a memória, podem ultrapassar muros e gerar novos sentidos de vida, e quem sabe também, outros acontecimentos, antes inimagináveis, em direção a uma outra recriação de si, mesmo que sejam apenas fagulhas.

\section{O que buscamos e o que faremos.}

Até aqui, apresentamos um breve panorama da situação do encarceramento feminino, a proposta de um projeto que está sendo desenvolvido com detentas, bem como as motivações sociais e pessoais que nos levaram a trabalhar com este "Jardim das Cerejeiras". Atrelado a nossa proposta, trouxemos pensadores que nos auxiliam a fundamentar nossos processos criativos práticos e teóricos. Cabe, nesse momento, explicitar o que buscamos e como estamos concretizando esta proposta. 
Temos como um dos nossos objetivos principais, estabelecer um processo de troca de conhecimento e experiência entre Universidade e Penitenciárias, através de uma vivência teatral nos âmbitos da apreciação, reflexão e produção artística. Dessa forma, a vivência teatral pautada na criação, apreciação e reflexão pode permitir estabelecer estratégias de empoderamento (recriação de si) do público-alvo, que encontra-se em um espaço de privação de liberdade. Ao instigar a percepção psicofísica e a capacidade de criação em espaços de cárcere, entendemos também, o exercício formativo, criativo e cidadão, dos estudantes da academia em ações extensivas como essa. Buscar nas ações extensivas, uma forma integrada e interdisciplinar de extravasar os conteúdos acadêmicos e contribuir para o desenvolvimento da sociedade como um todo, acreditamos, tarefa basal da formação acadêmica.

Em relação aos aspectos filosóficos e poéticos dos temas tchekovianos, nosso projeto pretende favorecer um processo de difusão e, ao mesmo tempo, de reflexão sobre os mesmos. Buscamos aprofundar estes temas através da produção de novos saberes a partir da percepção das detentas e levando o teatro a um espaço onde habitualmente não está, seguido ainda de debates e oficinas de criação.

Além da intenção de buscar resultados férteis para as detentas e para nós, através da experimentação do universo tchekoviano, visamos ainda possibilitar aos estudantes de graduação uma experiência no ensino de arte dentro de uma instituição prisional, um espaço não-convencional e com especificidades muito complexas. Através da realização de oficinas, será possível a conexão tanto entre as detentas quanto destas com a equipe de alunos, professora e voluntários do projeto. Esses contatos possibilitam refletir acerca da importância do trabalho em grupo, estimulando uma abordagem da aprendizagem através da prática artístico-pedagógica, fazendo-a ir além da sua aplicação imediata e exercitando o sujeito criador, respondendo a desafios, sendo capaz de gerar saberes e mantendo a habilidade de aprender e recriar permanentemente.

Além das detentas e dos alunos, também atentamos para a equipe de servidores da SUSEPE$^{7}$, visando sensibilizá-los para a apreciação e a reflexão do fazer teatral. Em relação à universidade, desejamos gerar produções escritas, de cunho científico, a fim de registrar e divulgar a ação, auxiliando na criação de projetos afins, acompanhando e avaliando, periodicamente, o desenvolvimento das atividades, oferecendo parâmetros de avaliação do cumprimento de metas, esperando maximizar as chances de sucesso das ações.

\footnotetext{
${ }^{7}$ Superintendência dos Serviços Penitenciários do Estado do Rio Grande do Sul.
} 
Dessa forma, acreditamos ainda que o projeto nos permita praticar a indissociabilidade entre o ensino, a pesquisa e a extensão, promovendo a aquisição de conhecimentos técnicocientíficos integrados a realidade social.

Após apresentar os objetivos que visamos atingir, passamos a apresentar a metodologia empregada na atividade que estamos desenvolvendo. De forma geral, o projeto encontra-se dividido em oito etapas. Essas etapas não se sucedem de forma linear, sendo revistas e rearticuladas sempre que necessário. Para fins de sistematização, apresentamos as etapas no quadro a seguir:

Quadro 1: Etapas/ metodologias do Tempo de Impermanência: Teatro em Penitenciárias Femininas do Rio Grande do Sul

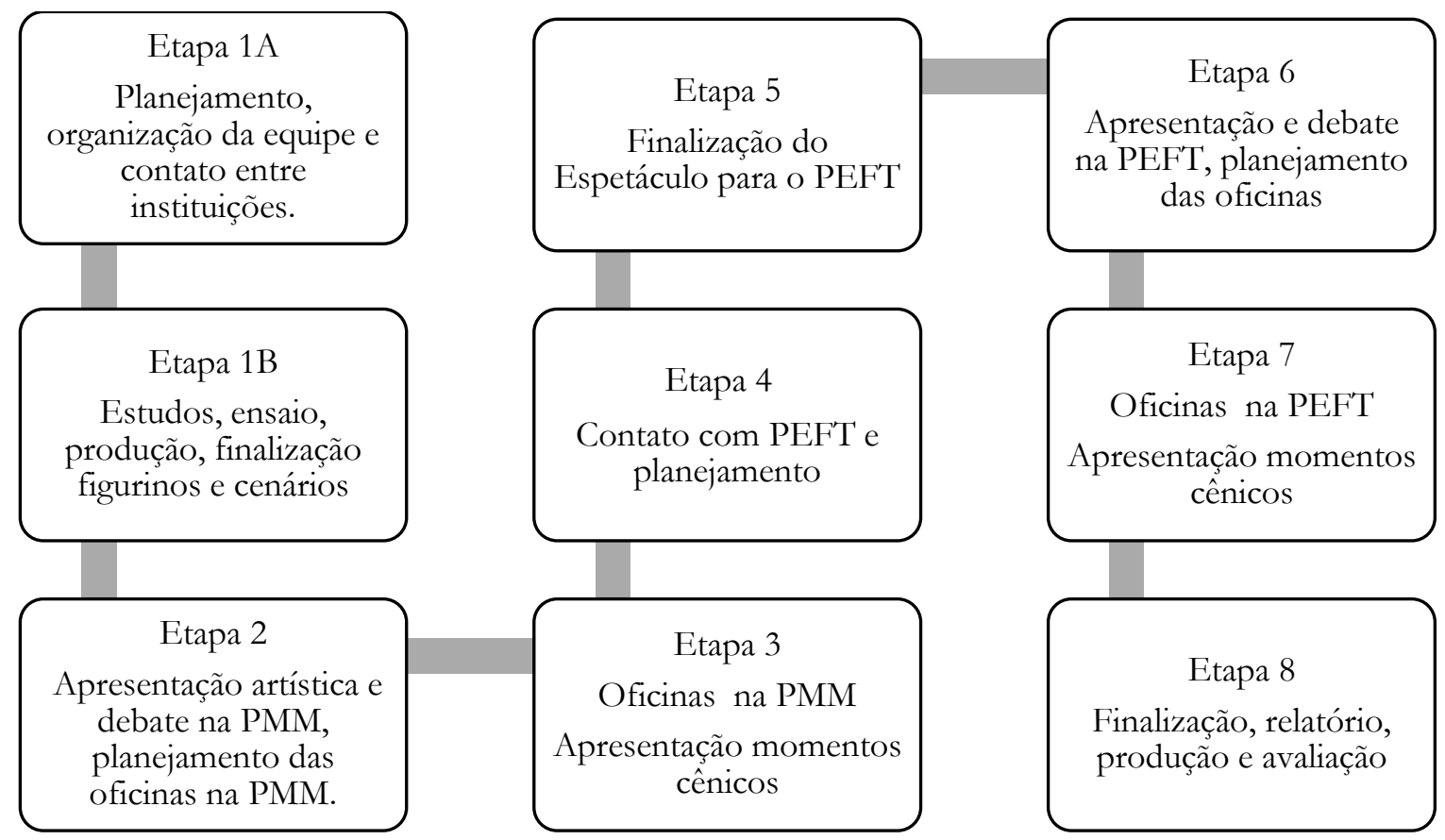

Fonte: Elaborado pelos autores

Conforme observamos no quadro, a primeira etapa, já realizada, contou com duas fases específicas. A primeira refere-se ao planejamento do projeto, organização da equipe de trabalho e o contato com a Superintendência de Serviços Penitenciários (SUSEPE), a Penitenciária Modulada de Montenegro-RS e com o Presídio Estadual Feminino de Torres/RS. Nesse momento fez-se o encaminhamento para a realização formal do convênio entre Universidade Estadual do Rio Grande do Sul e SUSEPE, cuja efetivação se deu a partir de um Termo de Colaboração entre as instituições. Dessa forma, o planejamento de todas as ações do projeto foram tomadas em comum acordo com SUSEPE, Penitenciárias e Uergs. 
Enquanto a primeira fase desta etapa, contou com o trabalho burocrático de formação das esquipes e articulação entre as instituições parceiras, a segunda fase, ocorrendo em paralelo, foi destinada a estudos, ensaios, produção e finalização de figurinos e cenários. Em relação aos estudos, o grupo procurou se aprofundar sobre o tema "teatro e penitenciária", utilizando-se das mais variadas fontes: bibliografia, artigos, vídeos, filmes, reportagens e depoimentos de apenadas.

A segunda etapa consiste, inicialmente, na apresentação artística e debate com as detentas da Penitenciária Modulada de Montenegro (PMM). Estão previstos nove encontros no presídio, sendo um deles destinado a esta apresentação do espetáculo: "O Jardim das Cerejeiras". Após o espetáculo, pretende-se realizar um debate sobre sua temática, articulando equipe do projeto, apenadas e funcionários da penitenciária. Depois de apresentar o espetáculo e realizar o debate, pretende-se planejar e executar as oficinas a serem realizadas na PMM, bem como avaliar o processo realizado até aquele momento.

A terceira etapa traduz-se na realização de oficinas com as apenadas da PMM, bem como a apresentação dos momentos cênicos, sendo uma criação teatral produzida pelas próprias apenadas durante as oficinas. Durante o processo de realização das oficinas continuaremos com o processo de pesquisa, finalizando com a avaliação desta etapa.

A quarta etapa consiste no contato com o Presídio Estadual Feminino de Torres (PEFT), atividade que acontecerá em paralelo ao planejamento das atividades a serem nele realizadas, bem como com a organização da equipe de trabalho. A quinta etapa será justamente a finalização da produção, logística e transporte, a serem executadas no PEFT, seguida da sexta etapa, composta pela apresentação e debate na PEFT e da sétima, na qual serão realizadas as oficinas e apresentação dos momentos cênicos com as detentas da PEFT.

A oitava e última etapa compreende a finalização do projeto. Neste momento, temos a intenção de produzir artigos e materiais de divulgação dos resultados obtidos, visando contribuir com a construção crítica de conhecimento ligado ao teatro em penitenciárias. Nestes artigos, pretendemos utilizar os materiais produzidos a partir da pesquisa de grupo bem como produzidos juntamente com as apenadas. Além da circulação de conhecimentos, realizaremos relatório e avaliação final do projeto. Os passos das ações serão divulgados num blog, alimentado pelo grupo, conforme o andamento do projeto. 


\section{Frutos a colher.}

Como apontamos anteriormente, nestes momentos nos encontramos finalizando a primeira etapa e ajustando questões burocráticas que permitirão dar início a segunda, na qual faremos a entrada nas penitenciárias. No entanto, apesar do longo percurso ainda a ser percorrido, já podemos apontar alguns resultados parciais.

Inicialmente a possibilidade concreta de poder levar o teatro e a cultura a lugares onde habitualmente não acontecem. A possibilidade de, mesmo em situação de cárcere, saber do humano como alguém suscetível ao crescimento, à sensibilização, à mudança, à capacidade crítica e ao próprio empoderamento.

Além disso, destacamos o maior acesso aos aspectos filosóficos e poéticos dos temas de Tchekov, tanto por parte da equipe do projeto quanto pelo público, a possibilidade de conhecer um autor clássico, que por isso mesmo, um autor que fala indistintamente ao espírito humano, independente de época e lugar. Em relação ao alunos da UERGS, o projeto tem permitido a ampliação do conhecimento e do seu exercício profissional, uma vez que entram em contato com espaços não convencionais de construção e atuação teatral.

Cabe destacar a troca de conhecimentos e experiências realizadas entre instituições, o fortalecimento da conexão entre a universidade e a penitenciária, em especial nos âmbitos da apreciação, reflexão e produção artística. Essa troca pode ser observada, por exemplo, na sensibilização das equipes de servidores da SUSEPE e das penitenciárias, que são levados à reflexão do fazer artístico.

Embora as entradas na penitenciária ainda não tenham ocorrido, através daquele contato inicial, anterior a este projeto, constatamos que atividades como essa podem promover a ampliação da percepção de si e da capacidade de criação e de empoderamento nas pessoas envolvidas. Além disso, observou-se também que, a partir do exercício teatral, vínculos solidários são criados entre todos.

Iniciamos este percurso com uma citação de Pfaller (2017), mostrando como o sistema penal foi feito e pensado por homens e para homens. Além disso, evidenciamos o processo de invisibilidade das detentas femininas, processo que queremos atritar, num movimento de resistência. Acreditamos que o Teatro pode ser uma possibilidade, mesmo que tênue, de promover uma pequena luz que dê visibilidade a estas mulheres, a partir da produção de artigos, matérias na mídia e apresentação em salões de pesquisa, tanto da nossa universidade quanto fora dela. Esse texto é mais uma tentativa de mostrar que sim, 
existe vida dentro de uma penitenciária e que esta pode ser considerada como um espaço potente para se pensar e fazer arte.

\title{
IMPERMANENCE TIME: THEATER IN WOMEN'S PRISONS
}

\begin{abstract}
This article presents the project "Impermanence Time: Theater in woman's prisons of Rio Grande do Sul", university extension action proposed by teacher and students of the XXXXXX course of XXXXXXXXXXX. The project focuses on theatrical activities directed to two prisons of the $1^{\mathrm{a}}$ Delegacia Penitenciária Regional do Estado do Rio Grande do Sul - the Penitenciária Modulada de Montenegro (PMM) and the Presídio Estadual Feminino de Torres (PEFT). In the text the invisibility of female imprisonment and the possibilities of theatrical actions in these institutions are discussed, some of the steps to be covered by the project are pointed out, and part of the results already obtained. The project is based on the possibility of theatrical performance in unconventional spaces and on the indissociability between teaching, research and university extension, dialoguing with the authors Brook (1995), Maria da Gloria Gohn (2004) and Henri Bergson (2006).
\end{abstract}

Feywords: University Extension. Woman's Prisons. Theater.

\section{Referências}

A LIGA. Presos falam com Cazé sobre relação com homossexuais no presídio. Reportagem exibida em: 19/07/2016. Disp. em: https://www.youtube.com/watch?v=cOPSc4amfQI. Acesso em 17 /06/2018.

BERGSON, Henri. Matéria e memória: ensaio sobre a relação do corpo com o espírito. São Paulo: Martins Fontes, 2006.

BROOK, Peter. O ponto de mudança: quarenta anos de experiências teatrais: 19461987. Rio de Janeiro: Civilização Brasileira, 1995.

A porta aberta: reflexões sobre a interpretação e o teatro. Rio de Janeiro: Civilização Brasileira, 1999.

CORREIA, André Brito. Teatro fora dos teatros. Arte dramática na prisão, no Jardim e no Bairro. In: Revista Crítica de Ciências Sociais, nº 67, 2003. p. 1-16.

GOHN, Maria da Gloria. Empoderamento e participação da comunidade em políticas sociais. In: Saúde e Sociedade, v. 13, n. 2. P. 20-31, maio- ago. 2004. 
PFALLER, Petra. O sistema penal foi feito e pensado por homens, para homens.

Entrevista cedida ao Sul 21. Disp. em: http://www.sul21.com.br/jornal/o-sistema-penal-foifeito-e-pensado-por-homens-para-homens-diz-irma-que-trabalha-com-presas. Publicado em 13 de maio de 2017. Acesso em 17/06/2018.

PROFISSÃO REPÓRTER. Presídio Central de Porto Alegre tem 2400 detentos acima da capacidade. Reportagem exibida em 10/11/2015. Disponível em:

https://www.youtube.com/watch?v=K1Rjfx3OiqM. Acesso em 17 /06/2018.

STECANELA, Nilda. CRAIDY, Carmen. Ecos de um cotidiano juvenil: as escritas de si na privação de liberdade. In: Conjectura, Caxias do Sul, v. 15, n. 3, set/dez. 2010.

TCHKOV, Anton. O jardim das cerejeiras. Tradução de Millôr Fernandes. Porto Alegre: L\&PM Editores, 1983. 